\title{
Review
}

\section{Recent updates and perspectives on leishmaniasis}

\author{
Dianella Savoia \\ Department of Clinical and Biological Sciences, University of Torino, Italy
}

\begin{abstract}
Leishmaniasis is a neglected vector-borne tropical infection considered to be a disease of the poor. Concentrated in poverty-stricken countries within Southeast Asia, East Africa, and Latin America, it is also endemic in several Mediterranean countries. The management of the heterogeneous syndromes determined by parasites belonging to the genus Leishmania is particularly difficult in developed, non-endemic countries owing to the unfamiliarity of physicians with clinical symptoms, diagnostic possibilities, and available treatment options. Therefore, travelers and other people who may be exposed to sand flies in endemic areas should receive counseling regarding leishmaniasis and appropriate protective measures. Serological diagnosis is rarely used for cutaneous and mucocutaneous diseases, but it is the most commonly used technique for visceral leishmaniasis. The drugs used to treat this last disease are expensive and sometimes have toxic side effects.

This review highlights the diagnostic, chemotherapeutic, and immunizing strategies to control leishmaniasis, though no human vaccine is commercially available currently owing to the complexity of the cellular immune response to this parasite.
\end{abstract}

Key words: leishmaniasis; diagnosis; treatment; immunotherapy.

J Infect Dev Ctries 2015; 9(6):588-596. doi:10.3855/jidc.6833

(Received 03 March 2015 - Accepted 10 April 2015)

Copyright $\odot 2015$ Savoia This is an open-access article distributed under the Creative Commons Attribution License, which permits unrestricted use, distribution, and reproduction in any medium, provided the original work is properly cited.

\section{Introduction}

Leishmaniasis is a neglected vector-borne tropical infection that is considered to be a disease of the poor [1].

Concentrated in poverty-stricken countries within Southeast Asia, East Africa, and Latin America, it is also endemic in several Mediterranean countries [2]. On a global scale, $\sim 350$ million people live in areas characterized by active transmission of Leishmania, with 14 million people directly affected by the disease [2]. There are three main types of leishmaniasis: visceral (kala-azar), the most important disease; cutaneous, the most common; and mucocutaneous. Among parasitic diseases, mortality from leishmaniasis is second only to malaria and, in terms of disability-adjusted life years (DALYs), the thirdmost common cause of morbidity after malaria and schistosomiasis, with children under 15 years of age suffering most of the disease burden. International traveling has caused an increase of leishmaniasis cases in non-endemic countries, making the recognition of this parasitic infection important [4]. Moreover, the increase of immunosuppressed individuals, secondary to human immunodeficiency virus (HIV) infection and post-transplant and chemotherapeutic agents, has resulted in an increase of visceral leishmaniasis in
Europe [5,6]. Kala-azar, the most deadly parasitic disease after malaria, spread by sand fly bites, afflicts hundreds of thousands of the world's poorest people in tropical countries. This vector-borne protozoan infection has clinical spectrum ranges from asymptomatic infection to fatal visceral leishmaniasis.

As reported by Alvar et al. [6], the number of cases of visceral leishmaniasis (VL) is calculated to be as high as 0.2-0.4 million people per year, with more than $90 \%$ of these occurring in India, Bangladesh, Sudan, Ethiopia, and Brazil, with a mortality estimated at 10\%-20\%, especially in poor areas. Cutaneous leishmaniasis (CL), considered by the World Health Organization (WHO) a category 1 emerging and uncontrolled disease [7], occurs mainly in the Mediterranean littoral, the Americas, and western Asia; up to $75 \%$ of these cases are found in Brazil, Syria, and Afghanistan. Approximately 35,000 cases of mucosal leishmaniasis occur annually, mainly in Brazil, Peru, and Bolivia [2]. In European countries, only two Leishmania species are endemic: $L$. infantum, responsible for zoonotic cutaneous and systemic disease within the Mediterranean region, with a reservoir in the domestic dog; and L. tropica, causing sporadic cases of anthroponotic cutaneous disease mainly in Greece. Autochthonous transmission 
has been reported in Portugal, Spain, France, Italy, Greece, Malta, Cyprus, Croatia, Albania, Bulgaria, and Turkey. Most are sporadic endemic diseases, but recent outbreaks of leishmaniasis have occurred in Spain and Italy $[8,9]$. A recent case described by de Silva et al. [10] emphasizes the importance of a differential diagnosis in the presence of compatible skin lesions following foreign travel.

$\mathrm{VL}$ is hypoendemic in Mediterranean countries; cases in this area account for 5\%-6\% of the global burden. It does not necessarily lead to clinical disease; most infections remain asymptomatic, but malnutrition and immune suppression, notably HIV, predispose to clinical diseases [5]. Cases of Leishmania/HIV coinfection have been reported in the Mediterranean region, mainly in France, Italy, Portugal, and Spain [11]. Since highly active antiretroviral therapy was introduced in 1997, a marked decrease in the number of co-infected cases both in these regions and in India have been reported [12]. VL is a rare disease in solidorgan transplant recipients. Clemente et al. [13], in a multicenter study, determined the risk factors and outcomes of VL in these patients. They observed that diagnosis was frequently delayed and relapses were common after treatment.

Despite a tentative estimate of mortality of 20,000-40,000 VL deaths per year, leishmaniasis belongs to the group of neglected tropical diseases. In 2007, the World Health Assembly approved a resolution on the control of leishmaniasis, and the WHO established control programs. In 2010, an expert committee concluded that adequate worldwide leishmaniasis control is feasible but that there is a crucial lack of political commitment and international cooperation. This disease remains a major neglected tropical disease, and a strategic framework for its control in the WHO European region has been recently applied [14].

These intracellular protozoa have a complex digenetic life cycle, requiring a susceptible vertebrate host and a permissive insect vector, which allow their transmission. Diniz et al. [15] emphasized the importance of animal reservoirs in facilitating transmission of VL in densely populated urban areas in Brazil, and recently, Turchetti et al. [16] discussed the role of sexual and vertical transmission of this disease in canine populations playing an important role in the maintenance of VL.

As a result of a long host-parasite co-evolutionary process, Leishmania spp. has developed different immunomodulatory strategies that are essential for the establishment of infection. Understanding the mechanisms associated with immune evasion and disease progression is essential for the development of novel therapies and vaccine approaches. Cecilio et al. [17] recently revised how the parasite manipulates cell death and immune responses to survive. The parasite can alter the maturation process of the phagolysosome, modulate cytokine and chemokine production by host cells, impairing cell function, to enter host cells and successfully differentiate and infect.

A review concerning outbreaks in Israel over a recent 13-year period revealed an expansion of CL illness in southern, central, and northern areas of the country [18]. Therefore, studies of the responsible factors and a greater degree of public alertness are necessary. Zoonotic CL due to $L$. major is still a serious public health problem also in Tunisia. Researchers comparing the prevalence and risk factors in old and new foci using leishmanin skin test (LST) in central Tunisia observed [19] that the overall prevalence of LST positivity was $57 \%$, and was significantly higher in the old focus than in the emerging foci. In 2012, a CL outbreak was observed among Syrian refugees in Lebanon [20] due to $L$. tropica and L. major infection in $85 \%$ and $15 \%$ of patients, respectively. These infections were cured in $82 \%$ of the cases by megulamine antimonite therapy for three months. An unusual presentation of imported L. infantum CL, diagnosed in an Australian who had traveled in Italy 19 years before, has been reported [21], supporting the importance of parasite persistence evaluation in the diagnosis of this infection.

Climate changes in Europe have increased the spread of new vectors. In northern Italy, leishmaniasis has been associated with climatic conditions that favor the development of the vector Phlebotomus perniciosus $[22,23]$. The increase of VL cases is also related to immunodepression and other variables, such as the increase of international travel, migration, and trade, which present the risk of importing parasites, vectors, and infections [24]. The main area for the acquisition of CL, especially for adventure travelers on long-term trips in highly endemic forested areas, is South America, whereas popular Mediterranean destinations are emerging as the main areas to acquire the visceral variant. The management of these infections in developed, non-endemic countries is still difficult owing to the unfamiliarity of physicians with clinical syndromes, diagnostic possibilities, and available treatment options. Therefore, travelers and other people who could be exposed to sand flies in endemic areas should receive counseling regarding leishmaniasis and appropriate protective measures. 


\section{Diagnosis}

Most VL infections are diagnosed clinically with observation of irregular fever, anemia, leucopenia, and hepatosplenomegaly [2], but there are several methods of laboratory diagnosis of leishmaniasis. As recently reported [25], these include parasite detection by microscopic examination, culture and successive isoenzyme analysis for identification, or molecular biology-based assays for detecting the parasite DNA (polymerase chain reaction [PCR]). These last tests are more sensitive, but may be applied only in particular centers. Different PCR methods have been evaluated $[26,27]$ and have been found to demonstrate a superior sensitivity compared with microscopy smear and in vitro culture.

Serological diagnosis, even if rarely used for CL and mucocutaneous leishmaniasis (MCL) disease, is the technique more commonly used for VL [25]. Various techniques are employed, including Immunofluorescence antibody assay (IFA), enzymelinked immunosorbent assay (ELISA), western blot, rapid strip testing for rK39 antigen, direct agglutination technique, or detection of Leishmania antigen in urine by latex agglutination. High serum antibody levels are present in both asymptomatic and active VL and remain present for several years. However, the specificity of these tests in VL-endemic areas is variable, and in Leishmania/HIV coinfections, the serological approach for diagnosis is difficult owing to the immunosuppressive action of the virus. In fact, in these cases, additional molecular or other parasitological tests may be necessary if the results of the serological tests are negative.

Mohapatra et al. [28] conducted a comparative evaluation of different recombinant antigens for the serodiagnosis of Indian visceral leishmaniasis. They concluded that rK39 (a 39-aminoacid-repetitive immunodominant B-cell epitope of kinesin-related antigen from $L$. chagasi) was the most suitable antigen when compared with rK26 and rK9; this last antigen may be used as an adjunct to rK39 for accurate diagnosis of VL. The diagnostic antigens rK26 and rK18 were demonstrated to be suitable to be used as an indirect measure of parasite clearance after therapy [29]. The ELISA technique effected with a recombinant $L$. infantum heat shock protein 83 (rHsp83) represents a routine confirmatory serological assay for the diagnosis of CL, MCL, and VL [30]. Integrated diagnosis based on clinical symptoms together with an rK39 immunochromatographic rapid test is commonly used, whereas a combination of molecular and serological tests are especially useful for asymptomatic infections in endemic areas [25]. Leishmaniasis should be considered in the diagnostic assessment of patients with a compatible clinical syndrome and a history of traveling in an endemic area, even if it occurred several months or years before [21].

\section{Treatment}

The drugs employed to treat VL are expensive and sometimes have toxic side effects.

A recent review of new chemotherapeutic strategies against malaria, leishmaniasis, and trypanosomiasis [31], reports the updated literature on the challenges of drugs against leishmaniae.

Liposomal amphotericin B has the best safety profile and has been approved by the Food and Drug Administration (FDA) for the treatment of VL [32] and is the drug most used in species-directed therapy of leishmaniasis in returning travelers [33].

A multicenter, open-label study evaluated the efficacy and safety of two treatment options, single infusion of preformed amphotericin $\mathrm{B}(\mathrm{AmB})$ lipid emulsion (ABLE) and liposomal formulation (LAmB); the first type of infusion was found to be more effective and better tolerated [34]. Resveratrol, a polyphenol found in black grapes and red wine that has many biological activities, in association with amphotericin B, showed synergy against $L$. amazonensis in vitro [35].

Other drugs that have been brought onto the market more recently are paromomycin and miltefosine. The first is an aminoglycoside antibiotic, which was granted orphan drug status in 2005, and is used for the treatment of both VL and CL in parenteral and topic formulations [36]. Miltefosine was registered in India in 2002 as the first oral antileishmanial agent; its major limitations are the high cost, the need for monitoring of gastrointestinal side-effects, and occasional hepatic and renal toxicity [37]. Combining paromomycin with miltefosine, the release of nitric oxide and tumour necrosis factor by human macrophages was induced, enhancing the killing of $L$. donovani promastigotes in vitro [38]. Fexinidazole (formerly Hoe 239), an oral nitroimidazole, was rediscovered by the Drugs for Neglected Disease initiative (DNDi) and is in clinical trials for the treatment of African sleeping sickness; this compound or another nitroimidazole, PA-824, may be effective against leishmaniae [39].

The synthesis of polyamines and of their precursors is essential for Leishmania protozoa; therefore, the enzymes involved in spermidine 
synthesis and utilization, in particular trypanothione synthetase and trypanothione reductase, are attractive targets for drug development [40].

Also, peptidases (proteases) are enzymes that are considered interesting targets for chemotherapy $[31,41]$. The only aspartic protease present in leishmaniae belongs to the family of the A2 retrovirallike aspartic proteases and is inhibited by drugs originally developed as inhibitors of HIV protease [42,43]. A recent review [42] summarizes the biology of kinetoplastid topoisomerases, which can be molecular targets in antileishmanial chemotherapy, as observed with pefloxacin in 1996 [45].

In Leishmania, dihydrofolate reductase (DHFR) forms a functional complex with thymidylate synthase (TS). By means of an in silico virtual screening technique, many DHFR-TS based drugs were screened; among these, the molecule 571633 proved promising and deserves further development [46].

High-throughput screening has also been used to identify molecules based on new molecular scaffolds. CA272 and CH872 are two molecules, based on the hydrazine and 4-hydroxyquinoline scaffolds, respectively, that are new promising antileishmanial compounds [47].

Prati et al. [48] investigated the feasibility of targeting Leishmania transporters via appropriately designed chemical probes. L. donovani is auxotrophic for arginine and lysine and has specific transporters (LdAAP3 and LdAAP7) to import these nutrients. Some conjugates containing cytotoxic quinone fragments (II and III) linked to amino acids (arginine and lysine) displayed toxicity against the parasites and not against mammalian THP1 cells. Recently, Nagle et al. [49] reported significant progress in the treatment of both leishmaniasis and African trypanosomiasis (HAT). However, new drugs for both diseases are still needed; two compounds were in clinical trials for HAT (nifurtimox and SCYX-7158) and one for VL (nifurtimox). Gupta et al. [50] recently identified a nitroimidazo-oxazole lead molecule for the treatment of VL. In particular, the compound DNDI-VL-2098 was characterized by a leishmanicidal activity and a capacity of inducing host-protective immune cells in hamsters. Moreover, some novel heteroretinoidbisbenzylidine ketone hybrids have been synthesized and evaluated by Tiwari et al. [51] for their in vitro activity against $L$. donovani; a new class of compounds with antileishmanial activity was identified. Also, $\mathrm{N}$-substituted $\beta$-amino alkanols were recently shown to have leishmanicidal activity, inducing severe mitochondrial swelling and vesiculation of the parasite [52].

A new delivery strategy that can increase drug distribution among different mononuclear phagocyte system tissues was studied [53]; pegylated meglumine antimoniate-containing liposomes (LMA) and their mixture with non-pegylated (conventional) LMA proved to be more effective in dogs and mice than did conventional LMA against VL. Crovirin, a cysteinerich secretory protein (CRISP), extracted from Crotalus viridis viridis snake venom, used with a highperformance liquid chromatographer, had promising results against trypanosomes and leishmania [54]. This family might have potential as drugs or drug leads for the development of novel agents against these protozoa.

Different natural products were assessed. De Queiroz et al. [55] investigated the leishmanicidal activity of five species of plants used in folk medicine in Brazil in patients with CL (L. amazonensis). The plant extracts Hyptis pectinata (L.) Poit, Aloe vera (L.), Ruta graveolens (L.), Pfaffia glomerata (Spreng) Pedersen, and Chenopodium ambrosioides (L.) exhibited direct activity against extracellular forms of Leishmania. Recently, thymol derivatives were assessed in mice, and were found to demonstrate greater activity than the eugenol derivatives; benzoylthymol was the best inhibitor with decreased toxicity [56]. These modified compounds are promising candidates for further studies of antileishmanial drug development. The leishmanicidal effect of essential oil from Artemisia annua leaves against $L$. donovani in vitro and in vivo was also reported [57].

Nadhman et al. [58] described daylight responsive silver (Ag) doped semiconductor nanoparticles of zinc oxide for photodynamic therapy (PDT) against Leishmania. These biocompatible nanoparticles demonstrated a daylight response, causing permeability of the cell membrane and the death of parasites. Daylight-activated photodynamic therapy (DA-PDT), which abolishes the need for artificial light sources, permitting auto-treatment of the patient, was found to be effective for CL caused by $L$. major and $L$. tropica [59]. Different macrocycles, i.e., cyclic macromolecules, such as sapphyrin and two related heterosapphyrins, have been investigated as potential agents for the treatment of leishmaniasis [60].

\section{Immunity and immunotherapy}

Vaccination to control leishmaniasis is promising, but at the moment, no human vaccine is commercially available due to different causes, but particularly due 
to the complexity of the cellular immune response to this parasite [2]. Vaccines against canine leishmaniasis, for the reduction of the transmission of L. infantum to people, have been tested in Brazil and Europe with mixed results. A recent study showed that first-generation canine vaccines have inadequate ability to produce long-lasting immunity [61]. Thirdgeneration vaccines are protective, but owing to the different nature of DNA antigens, their value is unclear. Second-generation vaccines could be one of the best choices for canine Leishmania vaccination. They consist of $L$. donovani glycoprotein (fucose mannose ligand) with saponin as an adjuvant. Recently, Gradoni [60] demonstrated that an effective canine Leishmania vaccine should induce strong and long-lasting Th1-dominated immunity to control both infection progression and parasite transmissibility via the vector. Promising antigens, including killed parasites, cell purified fractions, parasite protein components or subunits, single or multiple chimeric recombinant proteins, plasmid DNA and viral particles encoding parasite virulence factors, and adjuvant combinations have been tested on dogs. Limited or no protection was observed in phase I and II studies. The A2 antigen (a recombinant protein from the amastigote stage of different Leishmania species) plus saponin, which gave about $40 \%$ protection against infection, has been registered as a canine vaccine, LeishTec in Brazil and CaniLeish in Europe.

Prophylactic vaccination of both human VL carriers and dogs could generate long-term protection, reducing disease incidence. Therefore, different studies $[63,64]$ continue to refine both antigen and adjuvant components of vaccines, as well as identify the mechanisms associated with immune evasion and disease progression to develop novel vaccine approaches. Leishmania parasites activate the innate and adaptive arms of the immune system, and a coordinated network of responses is required for effective immune-mediated parasite clearance. In particular, one of the reasons for anti-leishmaniasis vaccine failure is the lack of an appropriate adjuvant. Chemokine and cytokine responses are essential; however, Leishmania parasites have developed numerous mechanisms to prevent the development of immunity; one of these is inducing immunosuppressive cytokines. Recently, different methodologies, which include proteomics, have identified new antigens for potential polyvalent synthetic and recombinant chimeric vaccine candidates [65].
VL pathogenesis has been correlated with an overproduction of the regulatory cytokine IL-10, responsible for disease progression, whereas cytokines that selectively induce Th1 responses might be useful for VL therapy [66]. Also, dendritic cells are important in initial anti-Leishmania $\mathrm{T}$ cell responses, promoting the differentiation into memory T cells. Dendritic cellbased immunotherapy combined with antimony-based chemotherapy has been studied in mice, revealing a promising synergy. The IFN $\gamma$ released by cells, particularly by $\mathrm{CD}+\mathrm{T}$ cells, from VL patients serves to limit parasite growth [67]. Arabinosylated lipoarabinomannan, a Toll-like receptor 2-ligand isolated from Mycobacterium smegmatis, has a strong immunomodulatory property, giving protection against $L$. donovani infection by restoring IFN- $\gamma$ responsiveness important for protection against $L$. donovani-susceptible hosts [68]. The role of interleukin 17 (IL-17), an inflammatory cytokine that plays a protective role against intracellular parasites, is controversial. Nascimento et al. [67], evaluating the levels of IL-17A in the sera from patients with VL before and at different times after treatment with Glucantime, noted higher levels in the sera of patients with VL before treatment than in normal or endemic controls; during treatment, the levels of IL-17A decreased, but remained significantly higher than the values of normal subjects. This cytokine acts synergistically with IFN- $\gamma$, increasing nitric oxide production and leishmanicidal activity in infected macrophages. Tumor necrosis factor $\alpha(\mathrm{TNF}-\alpha)$ is another cytokine that is important in Leishmania infections, controlling inflammatory lesions and parasite killing. A new strategy for leishmanial treatment is based also on Toll-like receptor signal pathways [70].

Though vitamin A supplementation proved to be effective in diarrheal and respiratory diseases in several countries, few studies examined the effect in VL. Lima Maciel et al. [69] analyzed the effect of this vitamin on regulatory $\mathrm{T}$ cells and monocytes isolated from symptomatic VL and from healthy children residing in an area endemic for VL; they demonstrated that vitamin A associated to VL therapy improved recovery.

Kaur et al. [70] recently studied herbal drugs derived as whole-plant extracts of Asparagus racemosus and Withania somnifera to treat $L$. donovani-infected BALB/c mice. Treatment with both extracts in combination was found to be effective against parasites, generating protective Th1-type immune responses. 
To identify new immunogens as vaccines in a murine model of VL, epitope-based immunogens, consisting of phage-fused peptides mimicking $L$. infantum antigens, were selected, and their affinity to antibodies from asymptomatic and symptomatic VL dogs' sera was studied [71]. Two phage clones expressing target mimotopes provided protection in mice against $L$. infantum correlated to a Th1-type immune response.

Previously, it was reported that liposomes associated with amphotericin B were used for Leishmania therapy [32]. Moreover, they have been found to be potent adjuvants for different antigens and are effective vehicles for peptides and proteins, increasing their immunogenicity. Liposomes carrying glycosylphosphatidylinositol-anchored proteins of $L$. amazonensis promastigotes could, in fact, induce protective immunity in mice [72].

\section{Conclusions}

Leishmaniasis is a major health problem worldwide. The spectrum of infection is subclinical (not apparent), localized (skin lesion), and disseminated (mucocutaneous and visceral); it depends on the immune status of the host, on the parasite, and on immune-inflammatory responses.

Major risk factors of Leishmania distribution are socioeconomic conditions, malnutrition, population mobility, and environmental and climate changes. Prevention and control are based on early diagnosis and treatment, vector control, disease surveillance, and education of the community. The European Union has been receiving, since the mid-1900s, an influx of immigrants, known to be a marginalized and vulnerable group, with an estimated 20 million migrants having arrived in the past 15 years [3]. Therefore, leishmaniasis should be considered in the diagnostic assessment of immigrants or travelers who could have been exposed to the parasite in endemic areas $[24,25]$.

This protozoan disease is second to malaria in importance for human health; however, the options for chemotherapeutic treatment are limited owing to drug resistance and toxicity. The drug of choice is still out of reach; among the chemotherapeutic strategies, the combination of local and parenteral therapies could be more effective, shortening the duration of the treatment. A new strategy, studied in vitro, is based on nanoemulsions containing cholesterol and amphotericin B; the encapsulation of the drug seems to increase its efficiency [73].
To combat VL, it is important to unite groups working on drugs for the disease into a single organization, the VL Global R\&D \& Access Initiative [74].

For immunity to Leishmania antigen, persistence is necessary [64]. L. major vaccine consisting of needle inoculation with viable $L$. major parasites in a selected site, referred to as leishmanization, has been used in the past for people living in regions endemic for cutaneous forms of leishmaniasis. This is not a vaccine in the conventional sense, even if the cultures were less virulent than the forms inoculated by the sand-fly vector. Its use was interrupted owing to severe primary lesions. Irradiated or genetically modified organisms could be used for immunization; however, priority should be given to clinical trials of defined, subunit vaccines against this parasitic disease. Promising antigens, single or multiple chimeric recombinant proteins, plasmid DNA and viral particles encoding parasite virulence factors, and adjuvant combinations have been tested. Prophylactic and immunotherapy vaccination of both humans and dogs could generate long-term protection, reducing disease incidence responsible for protean manifestations.

\section{Dedication}

This paper is dedicated to Prof. Piero Cappuccinelli, a brilliant scientist, teacher and friend. Piero is well-known worldwide as a visiting teacher in different prestigious institutions of several countries and for various projects. He has been a curious, eclectic and inventive scientist since his training in Microbiology and Parasitology at the University of Turin. I am proud to know him not only as a scientist and colleague but also as a friend.

\section{References}

1. World Health Organization (2014) Global Health Observatory Data - Leishmaniasis. Available at: http://www.who.int/gho/neglected_diseases/leishmaniasis/en/ Global Health Observatory. Accessed on April 21, 2015.

2. Pace D (2014) Leishmaniasis. J Infect 69 S10-18.

3. Khyatti M, Trimbitas RD, Zouheir Y, Benani A, El Messaoudi MD, Hemminki K (2014) Infectious diseases in North Africa and North African immigrants to Europe. Eur J Public Health 24 Suppl 1: 47-56.

4. Field V, Gautret P, Schlagenhauf P, Burchard GD, Caumes E, Jensenius M, Castelli F, Gkrania-Klotsas E, Weld L, LopezVelez R, de Vries P, von Sonnenburg F, Loutan L, Parola P; EuroTravNet network (2010) Travel and migration associated infectious diseases morbidity in Europe, 2008. BMC Infect Dis 10: 330 .

5. Okwor I, Uzonna JE (2013) The immunology of leishmania/HIV coinfection. Immunol Res 56: 163-171. 
6. Alvar J, Velez ID, Bern C, Herrero M, Desjeux P, Cano J, Jannin J, den Boer M; WHO Leishmaniasis Control Team (2012) Leishmaniasis worldwide and global estimates of its incidence. PLoS ONE 7: e35671.

7. De Vries HJ, Reedijk SH, Schallig HD (2015) Cutaneous leishmaniasis: recent developments in diagnosis and management. Am J Clin Dermatol 16: 99-109.

8. Arce A, Estirado A, Ordobas M, Sevilla S, García N, Moratilla L, de la Fuente S, Martínez AM, Pérez AM, Aránguez E, Iriso A, Sevillano O, Bernal J, Vilas F (2013) Re-emergence of leishmaniasis in Spain: community outbreak in Madrid, Spain, 2009 to 2012. Euro Surveill 18: 20546.

9. Varani S, Cagarelli R, Melchionda F, Attard L Salvadori C, Finarelli AC, Gentilomi GA, Tigani R, Rangoni R, Todeschini R, Scalone A, Di Muccio T, Gramiccia M, Gradoni L, Viale P, Landini MP (2013) Ongoing outbreak of visceral leishmaniasis in Bologna Province, Italy, November 2012 to May 2013. Euro Surveill 18: 20530.

10. de Silva TI, Debroy Kidambi A, Green ST, Mahadeva U, Mcgregor AC, Levy M, Hardcastle N (2015) Cutaneous leishmaniasis acquired during a brief visit to Cyprus. J Infect 70: 314-316.

11. Monge-Maillo B, Norman F, Cruz I, Alvar J, Lopez-Velez R (2014) Visceral leishmaniasis and HIV coinfection in the Mediterranean region. PLoS Negl Trop Dis 8, e3021

12. Singh $\mathrm{S}$ (2014) Changing trends in the epidemiology, clinical presentation, and diagnosis of Leishmania-HIV co-infection in India. Int J Infect Dis 29:103-112.

13. Clemente W, Vidal E, Girão E, Ramos AS, Govedic F, Merino E, Muñoz P, Sabé N, Cervera C, Cota GF, Cordero E, Mena A, Montejo M, López-Medrano F, Aguado JM, Fernandes P, Valerio M, Carratalá J, Moreno A, Oliveira J, Mourão PH, Torre-Cisneros J (2015) Risk factors, clinical features and outcomes of visceral leishmaniasis in solid-organ transplant recipients: a retrospective multicenter case-control study. Clin Microbiol Infect 21: 89-95.

14. World Health Organization, Regional Office for Europe (2014) Strategic framework for-leishmaniasis control in the WHO European Region 2014-2010. Available at: www.euro.who.int/_data/assets/pdf_file/0017/245330/ Accessed on day/month/year.

15. Diniz SA, Silva FL, Carvalho Neta AV, Bueno R, Guerra RM, Abreu-Silva AL, Santos RL (2008) Animal reservoirs for visceral leishmaniasis in densely populated urban areas. J Infect Dev Ctries 2: 24-33. doi:10.3855/jidc.318.

16. Turchetti AP, Souza TD, Paixao TA, Santos RL. (2014) Sexual and vertical transmission of visceral leishmaniasis. J Infect Dev Ctries 8: 403-407. doi:10.3855/jidc.4108.

17. Cecilio P, Perez-Cabezas B, Santarem N, Maciel J, Rodrigues V, Cordeiro da Silva A (2014) Deception and manipulation: the arms of Leishmania, a successful parasite. Front Immunol 5: 480 .

18. Gandacu D, Glazer Y, Anis E, Karakis I Warshavsky B, Slater P, Grotto I (2014) Resurgence of cutaneous leishmaniasis in Israel, 2001-2012. Emerg Infect Dis 20: 1605-1611.

19. Bettaieb J, Toumi A, Chlif S, Chelghaf B, Boukthir A, Gharbi A, Ben Salah A (2014) Prevalence and determinants of Leishmania major infection in emerging and old foci in Tunisia. Parasit Vectors 7: 386.

20. Saroufim M, Charafeddine K, Issa G, Khalifeh H, Habib RH, Berry A, Ghosn N, Rady A, Khalifeh I (2014) Ongoing epidemic of cutaneous leishmaniasis among Syrian refugees, Lebanon. Emerg Infect Dis 20: 1712-1715.

21. Crowe A, Slavin J, Stark D, Aboltins C (2014) A case of imported Leishmania infantum cutaneous leishmaniasis; an unusual presentation occurring 19 years after travel. BMC Infect Dis 14: 597.

22. Maroli M, Feliciangeli MD, Bichaud L, Charrel RN, Gradoni L (2013) Phlebotomine sandflies and the spreading of leishmaniases and other diseases of public health concern. Med Vet Entomol 27: 123-147.

23. Signorini M, Cassini R, Drigo M, Frangipane di Regalbono A, Pietrobelli M, Montarsi F, Stensgaard AS (2014) Ecological niche model of Phlobotomus perniciosus, the main vector of canine leishmaniasis in north-eastern Italy. Geospat Health 9: 193-201.

24. Mansueto P, Seidita A, Vitale G, Cascio A (2014) Leishmaniasis in travelers: a literature review. Travel Med Infect Dis 12: 563-581.

25. Elmahallawy EK, Sampedro Martínez A, Rodriguez-Granger J, Hoyos-Mallecot Y, Agil A, Navarro Mari JM, Gutierrez Fernandez J (2014) Diagnosis of leishmaniasis. J Infect Dev Ctries 8: 961-972. doi:10.3855/jidc.4310.

26. Lemrani M, Hamdi S, Laamrani A, Hassar M (2009) PCR detection of Leishmania in skin biopsies. J Infect Dev Ctries 3: 115-122. doi:10.3855/jidc.511.

27. Santos TR, Carreira VS, Ferrari HF, Moreira MA, Luvizotto MC (2014) Comparison of PCR with stained slides of bone marrow and lymph nodes aspirates with suspect diagnosis for leishmaniasis. Acta Tropica 140: 137-140.

28. Mohapatra TM, Singh DP, Sen MR, Bharti K, Sundar S (2010) Comparative evaluation of rK9, rK26 and rK39 antigens in the serodiagnosis of Indian visceral leishmaniasis. J Infect Dev Ctries 4: 114-117. doi:10.3855/jidc.544.

29. Vallur AC, Hailu A, Mondal D, Reinhart C, Wondimu H, Tutterrow Y, Ghalib HW, Reed SG, Duthie MS (2014) Specific antibody responses as indicators of treatment efficacy for visceral leishmaniasis. Eur J Clin Microbiol Infect Dis 34: 679-686.

30. Celeste BJ, Arroyo Sanchez MC, Ramos-Sanchez EM, Castro LG, Lima Costa FA, Goto H (2014) Recombinant Leishmania infantum heat shock protein 83 for the serodiagnosis of cutaneous, mucosal, and visceral leishmaniasis. Am J Trop Med Hyg 90: 860-865.

31. Zucca M, Scutera S, Savoia D (2013) New chemotherapeutic strategies against malaria, leishmaniasis and trypanosomiases. Curr Med Chem 20: 502-526.

32. Sinha PK, Bhattacharya S (2014) Single-dose liposomal amphotericin B: an effective treatment for visceral leishmaniasis. Lancet Glob Health 2: e7-8.

33. Hodiamont CJ, Kager PA, Bart A, de Vries HJ, van Thiel PP, Leenstra T, de Vries PJ, van Vugt M, Grobusch MP, van Gool $T$ (2014) Species-directed therapy for leishmaniasis in returning travellers: a comprehensive guide. PLoS Negl Trop Dis 8: e2832.

34. Sundar S, Pandey K, Thakur CP, Jha TK, Das VN, Verma N, Lal CS, Verma D, Alam S, Das P (2014) Efficacy and safety of amphotericin B emulsion versus liposomal formulation in Indian patients with visceral leishmaniasis: a randomized, open-label study. PLoS Negl Trop Dis 8: e3169.

35. Ferreira C, Soares DC, Nascimento MT, Pinto-da-Silva LH, Sarzedas CG, Tinoco LW, Saraiva EM (2014) Resveratrol is active against Leishmania amazonensis: in vitro effect of its 
association with amphotericin B. Antimicrob Agents Chemother 58: 6197-6208.

36. Sinha PK, Jha T.K, Thakur CP, Nath D, Mukherjee S, Aditya AK, Sundar S (2011) Phase 4 pharmacovigilance trial of paromomycin injection for the treatment of visceral leishmaniasis in India. J Trop Med 2011, 645203.

37. Sundar S, Singh A, Rai M, Prajapati VK, Singh AK, Ostyn B, Boelaert M, Dujardin JC, Chakravarty J (2012) Efficacy of miltefosine in the treatment of visceral leishmaniasis in India after a decade of use. Clin Infect Dis 55: 543-550.

38. Das S, Rani, M, Pandey K, Sahoo GC, Rabidas VN, Singh D, Das P (2012) Combination of paromomycin and miltefosine promotes TLR4-dependent induction of antileishmanial immune response in vitro. J Antimicrob Chemother 67: 23732378.

39. Wyllie S, Patterson S, Stojanovski L, Simeons FR, Norval S, Kime R, Read KD, Fairlamb AH (2012) The antitrypanosome drug fexinidazole shows potential for treating visceral leishmaniasis. Sci Transl Med 4: 119re1

40. Colotti G, Ilari A (2011) Polyamine metabolism in Leishmania: from arginine to trypanothione. Amino Acids 40: 269-285.

41. Pereira BA, Souza-Silva F, Silva-Almeida M, Santos-deSouza R, Gonçalves de Oliveira LF, Ribeiro-Guimarães ML, Alves CR (2014) Proteinase inhibitors: a promising drug class for treating leishmaniasis. Current Drug Targets 15: 11211131.

42. Savoia D, Allice T, Tovo PA (2005) Antileishmanial activity of HIV protease inhibitors. Int J Antimicrob Agents 26: 9294.

43. White RE, Powell DJ, Berry C (2011) HIV proteinase inhibitors target the Ddil-like protein of Leishmania parasites. FASEB J 25: 1729-1736.

44. Chowdhury S, Majumder HK (2015) Inhibitors of DNA topoisomerases as potential antileishmanial agents. In: Leishmania: Current Biology and Control. Publ Caister Academic Press, Ed: Adak S and Datta R, CSIR India.

45. Zucca M, Millesimo M, Giovarelli M, Diverio D, Musso T, Savoia D (1996) Protective role of the pefloxacin-IFN-gamma association in Leishmania major-infected mice. New Microbiol 19: 39-46.

46. Rajasekaran R, Chen YP (2012) Probing the structure of Leishmania major DHFR TS and structure based virtual screening of peptide library for the identification of antileishmanial leads. J Mol Model 18: 4089-4100.

47. Siqueira-Neto JL, Song OR, Oh H, Sohn JH, Yang G, Nam J, Jang J, Cechetto J, Lee CB, Moon S, Genovesio A, Chatelain E, Christophe T, Freitas-Junior LH (2010) Antileishmanial high-throughput drug screening reveals drug candidates with new scaffolds. PLoS Negl Trop Dis 4: e675.

48. Prati F, Goldman-Pinkovich A, Lizzi F, Belluti F, Koren R, Zilberstein D, Bolognesi ML (2014) Quinone-amino acid conjugates targeting Leishmania amino acid transporters. PLoS One 9: e107994.

49. Nagle AS, Khare S, Kumar AB, Supek F, Buchynskyy A, Mathison CJ, Chennamaneni NK, Pendem N, Buckner FS, Gelb MH, Molteni V (2014) Recent developments in drug discovery for leishmaniasis and human african trypanosomiasis. Chem Rev PMID 25365529.

50. Gupta S, Yardley V, Vishwakarma P, Shivahare R, Sharma B, Launay D, Martin D, Puri SK (2015) Nitroimidazo-oxazole compound DNDI-VL-2098: an orally effective preclinical drug candidate for the treatment of visceral leishmaniasis. $\mathrm{J}$ Antimicrob Chemother 70: 518-527.

51. Tiwari A, Kumar S, Shivahare R, Kant P, Gupta S, Suryawanshi SN (2015) Chemotherapy of leishmaniasis part XIII: design and synthesis of novel heteroretinoidbisbenzylidine ketone hybrids as antileishmanial agents. Bioorg Med Chem Lett 25: 410-413.

52. Abengózar MÁ, Bustos LA, García-Hernández R, Fernández de Palencia P, Escarcena R, Castanys S, del Olmo E, Gamarro F, San Feliciano A, Rivas L (2015) Mechanisms of action of substituted $\beta$-amino alkanols on Leishmania donovani. Antimicrob Agents Chemother 59: 1211-1218.

53. Azevedo EG, Ribeiro RR, da Silva SM, Ferreira CS, de Souza LE, Ferreira AA, de Oliveira E Castro RA, Demicheli C, Rezende SA, Frézard F (2014) Mixed formulation of conventional and pegylated liposomes as a novel drug delivery strategy for improved treatment of visceral leishmaniasis. Expert Opin Drug Deliv 11: 1551-1560.

54. Adade CM, Carvalho AL, Tomaz MA, Costa TF, Godinho JL, Melo PA, Lima AP, Rodrigues JC, Zingali RB, SoutoPadrón T (2014) Crovirin, a snake venom cysteine-rich secretory protein (CRISP) with promising activity against Trypanosomes and Leishmania. PLoS Negl Trop Dis 8: e3252.

55. De Queiroz AC, Dias Tde L, Da Matta CB, Cavalcante Silva LH, de Araújo-Júnior JX, de Araújo GB, Moura Fde B, Alexandre-Moreira MS (2014) Antileishmanial activity of medicinal plants used in endemic areas in northeastern Brazil. Evid Based Complement Alternat Med 2014: 478290

56. de Morais SM, Vila-Nova NS, Bevilaqua CM, Rondon FC, Lobo $\mathrm{CH}$, de Alencar Araripe Noronha Moura A, Sales AD, Rodrigues AP, de Figuereido JR, Campello CC, Wilson ME, de Andrade HF Jr. (2014) Thymol and eugenol derivatives as potential antileishmanial agents. Bioorg Med Chem 22: 62506255.

57. Islamuddin M, Chouhan G, Tyagi M, Abdin MZ, Sahal D, Afrin F (2014) Leishmanicidal activities of Artemisia annua leaf essential oil against visceral leishmaniasis. Front Microbiol 5: 626.

58. Nadhman A, Nazir S, Khan MI, Arooj S, Bakhtiar M, Shahnaz G, Yasinzai M (2014) PEGylated silver doped zinc oxide nanoparticles as novel photosensitizers for photodynamic therapy against Leishmania. Free Radic Biol Med 77: 230-238.

59. Enk CD, Nasereddin A, Alper R, Dan-Goor M, Waffe CL, Wulf HC (2014) Cutaneous leishmaniasis responds to daylight-activated photodynamic therapy: proof-of-concept for a novel self-administered therapeutic modality. $\mathrm{Br} \mathrm{J}$ Dermatol PMID 25363817.

60. Peña S, Scarone L, Serra G (2015) Macrocycles as potential therapeutic agents in neglected diseases. Future Med Chem 4: $1-28$.

61. Foroughi-Parvar F, Hatam G (2014) Vaccines for canine leishmaniasis. Adv Prev Med 2014: 569193.

62. Gradoni L (2015) Canine Leishmania vaccines: still a long way to go. Vet Parasitol 208: 94-100.

63. Sacks DL (2014) Vaccines against tropical parasitic diseases: a persisting answer to a persisting problem. Nat Immunol 15 : 403-405.

64. Khadem F, Uzonna JE (2014) Immunity to visceral leishmaniasis: implications for immunotherapy. Future Microbiol 9: 901-915. 
65. Joshi S, Rawat K, Yadav NK, Kumar V, Siddiqi MI, Dube A (2014) Visceral leishmaniasis: advancements in vaccine development via classical and molecular approaches. Front Immunol 5: 380.

66. Singh OP, Sundar S (2014) Immunotherapy and targeted therapies in treatment of visceral leishmaniasis: current status and future prospects. Front Immunol 5: 296.

67. Kumar R, Singh N, Gautam S, Singh OP, Gidwani K, Rai M, Sacks D, Sundar S, Nylén S (2014) Leishmania specific CD4 $\mathrm{T}$ cells release IFN $\gamma$ that limits parasite replication in patients with visceral leishmaniasis. PLoS Negl Trop Dis 8: e3198.

68. Chowdhury BP, Bandyopadhyay S, Das S, Majumder S, Jha MK, Majumdar SB, Saha B, Majumdar S (2015) The Hostprotective effect of arabinosylated lipoarabinomannan against Leishmania donovani infection is associated with restoration of IFN- $\gamma$ responsiveness. PLoS One 10: e0117247.

69. Nascimento MS, Carregaro V, Lima-Júnior DS, Costa DL, Ryffel B, Duthie MS, de Jesus A, de Almeida RP , da Silva JS (2014) Interleukin 17A acts synergistically with interferon $\gamma$ to promote protection against Leishmania infantum infection. J Infect Dis 211: 1015-1026.

70. Dasgupta S, Aghazadeh-Dibavar S, Bandyopadyay M (2014) The role of toll-like receptor agonists in the immunotherapy of leishmaniosis. An update and proposal for a new form of anti-leishmanial therapy. Ann Parasitol 60: 75-82.

71. Lima Maciel BL, Valverde JG, Rodrigues-Neto JF, FreireNeto F, Keesen TS, Jeronimo SM (2014) Dual immune modulatory effect of vitamin A in human visceral leishmaniasis. PLoS One 9: e107564.

72. Kaur S, Chauhan K, Sachdeva H (2014) Protection against experimental visceral leishmaniasis by immunostimulation with herbal drugs derived from Withania somnifera and Asparagus racemosus. J Med Microbiol 63: 1328-1338.

73. Costa LE, Goulart LR, Pereira NC, Lima MI, Duarte MC, Martins VT, Lage PS, Menezes-Souza D, Ribeiro TG, Melo MN, Fernandes AP, Soto M, Tavares CA, Chávez-Fumagalli MA, Coelho EA. (2014) Mimotope-based vaccines of Leishmania infantum antigens and their protective efficacy against visceral leishmaniasis. PLoS One 9: e110014.

74. Colhone MC, Silva-Jardim I, Stabeli RG, Ciancaglini P (2014) Nanobiotechnologic approach to a promising vaccine prototype for immunisation against leishmaniasis: a fast and effective method to incorporate GPI-anchored proteins of Leishmania amazonensis into liposomes. J Microencapsul 29: 1-8.

75. Caldeira LR, Fernandes FR, Costa DF, Frezard F, Afonso LC, Ferreira LA (2015) Nanoemulsions loaded with amphotericin B. a new approach for the treatment of leishmaniasis. Eur $\mathbf{J}$ Pharm 70C: $125-131$.

76. Hayden EC (2014) Projects set to tackle neglected diseases. Nature 505:142.

\section{Corresponding author}

Dianella Savoia

Dept. of Clinical and Biological Sciences, University of Torino,

S. Luigi Gonzaga Hospital, Regione Gonzole 10

10043 Orbassano (Torino), Italy

Phone: +39-0116705427

Fax: +39-0112365427

Email: dianella.savoia@unito.it

Conflict of interests: No conflict of interests is declared. 